\title{
Co-infection of Mycobacterium tuberculosis and Pneumocystis jirovecii in the Iranian Patients With Human Immunodeficiency Virus
}

\author{
Maryam Fatemeh Sheikholeslami ${ }^{1,2}$; Javid Sadraei ${ }^{1, *}$; Parissa Farnia ${ }^{2}$; Mehdi Forozandeh \\ Moghadam ${ }^{3}$; Hamid Emadi Kochak ${ }^{4}$ \\ ${ }^{1}$ Department of Parasitology, Tarbiat Modares University, Tehran, IR Iran \\ ${ }_{2}^{2}$ Mycobacteriology Research Center, National Research Institute of Tuberculosis and Lung Diseases (NRITLD), Shahid Beheshti University of Medical Sciences Tehran, IR Iran \\ 3 Department of Biotechnology, Tarbiat Modares University, Tehran, IR Iran \\ ${ }^{4}$ Iranian HIV/AIDS Research Center, Imam Khomeini Hospital, Tehran University of Medical Sciences, Tehran, IR Iran \\ *Corresponding author: Javid Sadraei, Department of Parasitology, Tarbiat Modares University, Tehran, IR Iran. Tel:+98-2182883841, Fax: +98-2182884555, E-mail: Sadraeij@modares.ac.ir
}

Received: December 29, 2013; Revised: June 9, 2014; Accepted: July 30, 2014

\begin{abstract}
Background: Based on the authors' knowledge, there is no study on the co-infection of opportunistic agents such as Mycobacterium tuberculosis and Pneumocystis jirovecii in the lungs of Iranian patients with immunosuppression.

Objectives: The current study aimed to show the rate of co-infection of M. tuberculosis and P. jirovecii in patients with Human Immunodeficiency Virus (HIV).

Patients and Methods: Forty-five pulmonary samples were collected from 30 patients with HIV who also infected with Tuberculosis and Pneumonia. All of the patients were admitted to two university hospitals of Mycobacteriology and the Iranian HIV|AIDS research centers. DNA of P. jirovecii was detected using nested-Polymerase Chain Reaction (nested-PCR) assay.

Results: All of the patients were male with the mean age of $32.95 \pm 7.15$ years. The mean of CD4 cell count was $109.25 \mathrm{cell} / \mathrm{mm}^{3}$. Of 30 patients with HIV, three (10\%) were co-infected with M. tuberculosis and P.jirovecii. No other causes of pneumonia were found in those three patients and CD4 cell counts less than 50 cell $/ \mathrm{mm}^{3}$ was reported.

Conclusions: The results of the current study showed a high rate of co-infection of $M$. tuberculosis and $P$.jirovecii in the Iranian patients with HIV. As the immune system condition worsened, the probability of occurrence of Pneumocystis Pneumonia (PCP) increased. Therefore, more specific, most rapid and sensitive tests should be utilized for diagnosis of PCP in this group of patients.
\end{abstract}

Keywords:Mycobacterium tuberculosis; Pneumocystis jirovecii; HIV; Co-infection

\section{Background}

Human Immunodeficiency virus (HIV) can infect and eliminate helper T-cells (CD4). Therefore, the ability of immune system to kill the germs such as bacteria, fungi, and viruses will be reduced due to elimination of these types of cells. The decreasing CD4 cell counts increase the susceptibility to opportunistic diseases. Consequently, HIV can cause the emergence of many opportunistic infectious diseases such as Tuberculosis (TB) and Pneumocystis Pneumonia (PCP), which are the most important and dangerous agents of pneumonia in immunosuppressed patients, especially those who are HIV positive (1). The prevalence of such diseases depends on geographical region and the CD4 cell count in the patients infected with HIV. While PCP was the most important and common reason of mortality in patients with HIV in the USA and European countries, before employing Highly Active Anti Retrovirus Therapy (HAART) and co-trimoxazole as prophylaxis against Pneumocystis jirovecii (2), Tuberculosis was the most prevalent infectious disease in the African regions $(3,4)$. Many reports are published on co- infection of more than one microorganism in most of the internal organs. However, there are few reports on the co-infection of an internal organ such as lung with two microorganisms (5-7).

\section{Objectives}

The current study aimed to evaluate the rate of co-infection with two opportunistic agents as P. jirovecii and Mycobacterium tuberculosis among the Iranian patients infected with HIV.

\section{Patients and Methods}

\subsection{Patients}

In the current retrospective study, forty-five pulmonary samples (39 sputum, four induced sputum, one bronchoalveolar lavage fluid, and one tracheal aspiration) were collected from 30 patients with HIV and positive results for M. bacilli in direct smear microscopy. The cases were selected among 126 patients with HIV referred to

Copyright (C) 2015, Ahvaz Jundishapur University of Medical Sciences. This is an open-access article distributed under the terms of the Creative Commons Attribution-NonCommercial 4.0 International License (http://creativecommons.org/licenses/by-nc/4.0/) which permits copy and redistribute the material just in noncommercial usages, provided the original work is properly cited. 
Sheikholeslami MF et al.

two referral centers, Iranian HIV/AIDS Research center (Imam Khomeini Hospital) and Mycobacteriology Research Center (Masieh Daneshvari Hospital) from August 2010 to March 2011. All of the patients showed at least one symptom of pneumonia including fever, cough with or without sputum, abnormal signs in their chest radiography, or computed tomography (CT) scan and pneumothorax. They were hospitalized because of pneumonia. Their CD4 cell count of the cases was under 200 cell $/ \mathrm{mm}^{3}$. HIV was diagnosed by ELISA test and confirmed through western blot. Data regarding HIV status and the result of direct smear microscopy of acid-fast bacilli were extracted from medical records of the patients. M. tuberculosis complex was diagnosed and differentiated from $M$. avium-intracellular complex by IS6110-Polymerase Chain Reaction (PCR), as previously described (8).

\subsection{DNA Extraction}

Pulmonary samples of the patients were decontaminated and neutralized by $4 \% \mathrm{NaOH}$ and $1 \% \mathrm{HCl}$, respectively. DNA was extracted using QIAamp DNA MiniKit (Qiagen, Germany) according to the instructions of manufacturer. Briefly, $20 \mu \mathrm{L}$ of proteinase K and $200 \mu \mathrm{L}$ of AL buffer were added to $200 \mu \mathrm{L}$ of homogenized sample and incubated at $56^{\circ} \mathrm{C}$ for 10 to 20 minutes. After adding $200 \mu \mathrm{L}$ of absolute ethanol to the solution, it was transferred to a spin column provided by QIAamp DNA MiniKit. Columns were washed twice with washing solution. Washing solution was discarded after centrifugation at $8000 \mathrm{rpm}$. Finally, $100 \mu \mathrm{L}$ of the elution buffer (EL) or distilled water was added to the spin column and incubated at room temperature for one minute. DNA was collected in a $1.5 \mathrm{~mm}$ microtube by centrifugation at $8000 \mathrm{rpm}$. Extracted DNA could be directly used for PCR or stored at $-20^{\circ} \mathrm{C}$ for later experiments.

\subsection{PCR Test}

A 260 base pair fragment of $\mathrm{mt}$ LSU rRNA gene of $P$. jirovecii was amplified by nested PCR. For the first round of PCR, two outer primers: PAZ102E:5'-GATGGCTGTTTCCAAGCCCA-3' and PAZ102H:5'-GTGTACGTTGCAAAGTACTC-3', and for the second step of PCR, two inner oligonucleotides: PAZ102-X: 5'-GTGAAATACAAATCGGACTAGG-3' and PAZ102-Y: 5'-TCACTTAATATTAATTGGGGAGC-3' were used as previously described (9-11). For the first round of PCR, $50 \mu \mathrm{g}$ of the extracted DNA was added to a $50 \mu \mathrm{L}$ PCR mix reaction containing: $10 \mathrm{mM}$ Tris- $\mathrm{HCl}, 3 \mathrm{mM} \mathrm{MgCl}, 0.4 \mathrm{mM}$ of each dNTP, 10 pmol of specific primers for the first round of PCR plus 1 unit of Hot starTaq® DNA polymerase (Qiagene, Germany). The thermal condition was provided by a thermo cycler machine (Astec, Japan) as follows: initial denaturation at $95^{\circ} \mathrm{C}$ for five minutes, followed by $35 \mathrm{cy}$ cles: $95^{\circ} \mathrm{C}$ for 30 seconds, $55^{\circ} \mathrm{C}$ for 40 seconds, $72^{\circ} \mathrm{C}$ for 60 seconds, and final extension at $72^{\circ} \mathrm{C}$ for 10 minutes. The second round of PCR was performed in the same condition except that instead of the target DNA, $5 \mu \mathrm{L}$ of amplicon from the first round of PCR was added to a mix containing inner specific primer.

\subsection{Detection}

To detect the desired bands, 260 bp of mt LSU rRNA gene, the PCR products were run on $1.5 \%$ agarose gel containing ethidium bromide and visualized under ultra violet (Figure 1). To prevent cross contamination, the steps of procedure were performed in separate completely equipped rooms. Distilled water was used instead of the target DNA as negative control in each step of the procedure. The DNA extracted from sputum of a patient with confirmed Pneumocystis pneumonia was used as positive control.

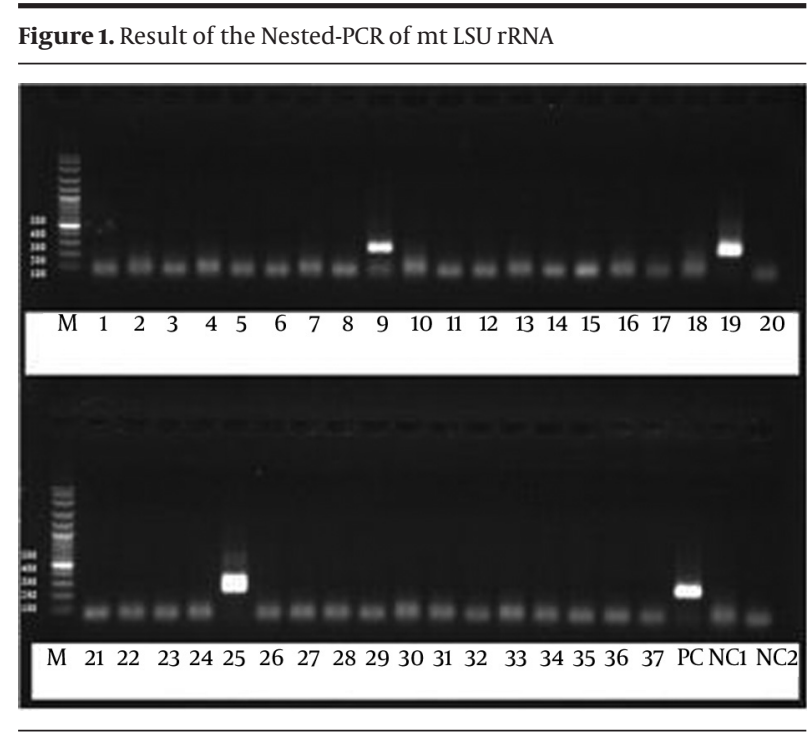

Lower row; M: 100 bp ladder, 25: P. jirovecii isolated from $\mathrm{HIV}^{+} \mathrm{TB}^{+}$patient, PC: positive control, NC1\& NC2: negative controls. Upper row; M: 100 bp ladder, 9 \& 19: P. jirovecii DNA isolated from two $\mathrm{HIV}^{+} \mathrm{TB}^{+}$patients.

\section{Results}

All of the patients with HIV introduced to this project were male with an average age of $32.95 \pm 7.15$ year (ranging from 18 to 69). The mean of CD4 cell counts was 109.25 cell $/ \mathrm{mm}^{3}$. Based on the protocol provided by the Ministry of Health and Medical Education of Iran, all of the patients were under TB treatment and they received ART (Anti Retroviral Therapy) and co-trimoxazol as prophylaxis against Pneumocystis pneumonia. The study results showed that the rate of tuberculosis among the Iranian patients with HIV was $42 \%$ (30 out of 126 cases) and three out of 30 cases with HIV (10\%) were co-infected with $M$. tuberculosis and P. jirovecii (Figure 1). No other infectious agents were detected in them. Notably, the CD4 cell counts of the patients co-infected with the mentioned microorganisms was under 50 cell $/ \mathrm{mm}^{3}$.

\section{Discussion}

Opportunistic bacterial and fungal diseases such as tu- 
berculosis and Pneumocystis pneumonia may cause fetal illness in patients with HIV (1). Among the opportunistic diseases, Pneumocystis pneumonia is more dangerous for immunosupprressed patients, especially in those infected with HIV. There are many reports on the co-infection of $P$. jirovecii with Cytomegalovirus, Cryptococcus spp., Aspergillus spp., Herpes simplex, Mycobacterium avium-intracellular complex in patients infected with HIV (12-14). However, there are few studies on the co-infection of an internal organ such as lung with two opportunistic microorganisms, P. jirovecii and M. tuberculosis, in these patients (5-7, 15). To the authors' best knowledge, the current study was the first on co-infection of Pneumocystis pneumonia and tuberculosis among the Iranian patients infected with HIV. Results of the current retrospective study showed the rate of co-infection with these two opportunistic microorganisms in Iranian patients with HIV as 10\%, which was similar to those of the African study (9.9\%) (16).

Before introducing ART and co-trimoxazole as a powerful prophylaxis against PCP in patients with HIV, Pneumocystis pneumonia was one of the most prevalent and lifethreatening diseases in the developed countries (17). On the other hand, the prevalence of tuberculosis was higher than PCP in South Africa and it was the most important and prevalent infectious disease in patients with HIV in this region $(3,4,17)$. Results of the current study indicated that the prevalence of tuberculosis in Iranian patients with HIV was $42 \%$. The previous studies revealed that the rate of PCP in these patients was $12.3 \%$ (18). Another study conducted in Ethiopia was concordant with the current study. Although, the rate of co-infection with these two microorganisms in Ethiopia was relatively higher (13.5\% of patients with HIV also infected with tuberculosis), it should be noted that, based on WHO reports the prevalence of tuberculosis in Iranian patients with HIV on ART and Co-trimoxazole Preventive Therapy (CPT) was significantly lower than those of the Ethiopian patients (18-20). Logically, the probability of co-infection with two microorganisms of $P$. jirovecii and $M$. tuberculosis was higher in regions with a high rate of TB.

Based on the protocol provided by the Ministry of Health and Medical Education of Iran, all of the infected patients with HIV received ART, Co-trimoxazole as a prophylaxis against PCP and Toxoplasmosis, especially when their CD4 cell counts were under $200 \mathrm{cell} / \mathrm{mm}^{3}$. Additionally, isoniazid as prophylaxis against LTBI was applied to the patients especially when they had close contact with TB patients or their PPD test (Purified Protein Derivative) had shown indurations. It seemed that, if Iranian patients with HIV were not under ART therapy and prophylaxis against PCP and they did not received isoniazid and rifampicin as the standard regimen for the tuberculosis treatment, the rate of co-infection of Pneumocystis pneumonia and tuberculosis would be higher. In contrast, infected patients with HIV in South African did not get prophylaxis against $P$. jirovecii and specific treatment against tuberculosis prior to clinical manifestation. Therefore, it could be supposed that the prevalence of $P$. jirovecii in South Africa was low in comparison to Iran. It was confirmed by earlier studies that the prevalence of PCP in Iranian patients with HIV positive was reported significantly higher than in the African adult patients with $\operatorname{HIV}(17,18,21,22)$.

Interestingly, the CD4 cell counts of the patients who coinfected with these two opportunistic microorganisms were reported less than $50 \mathrm{cell} / \mathrm{mm}^{3}$. It was confirmed that with the progress of HIV disease and worsening of the immune status, the probability of opportunistic and lifethreatening diseases such as Pneumocystis pneumonia would be higher (23). In the early phases of HIV, the rate of opportunistic diseases with high frequency such as tuberculosis would be higher, but with disease progression and immune deterioration, greater incidence of PCP, which is a disease with lower frequency, would be observed. Based on a study, patient with HIV were infected with tuberculosis when their CD4 cell counts were decreased to 206 cell $/ \mathrm{mm}^{3}$; whereas, the PCP occurred when their CD4 cell counts were $134 \mathrm{cell} / \mathrm{mm}^{3}(24)$. Although the number of patients who co-infected with these two microorganisms was low in the current study, the above rule was true.

The study was conducted in 30 cases out of 126 Iranian patients with HIV who their smear samples were positive in microscopy test for M. tuberculosis. The probability of PCP co-infection with tuberculosis among the patients of this category was high because tuberculosis was an endemic disease in Iran. With worsening the immune status patients with HIV, due to decrease of CD4 cell counts, the probability of Pneumocystis pneumonia occurrence will increase. The co-infection with these two microorganisms in patients with HIV was ignored most of the times, since the physicians were not aware of it. Therefore, the most rapid and sensitive tests to detect PCP should be applied and the patients should receive appropriate treatment.

\section{Acknowledgements}

Authors wish to thank Mycobacteriology Research Center for providing the facilities to conduct this project, and its personnel for doing smear direct microscopy and culturing the mycobacterium tuberculosis on the LeweenstienJehnsen medium. They also thank Dr. Payam Tabarsi, the nurses in Masihe Daneshvary Hospital, and Imam Khomeini as well as Risk Behaviors Counseling Center of Iranian HIV/AIDS Research Center for introducing HIV positive patients to the project. Tarbiat Modares University provided the project budget.

\section{Authors' Contributions}

Study concept and design: Javid Sadraei, and Maryam Fatemeh Sheikholeslami. Analysis and interpretation of data: Javid Sadraei, and Maryam Fatemeh Sheikholeslami. Drafting of the manuscript: Maryam Fatemeh Sheikholeslami. Critical revision of the manuscript for important intellectual content: Maryam Fatemeh Sheikholeslami, Javid Sadraei, Parissa Farnia, Mehdi Forozandeh Moghadam, Hamid Emadi Kochak. Statistical analy- 
sis: Javid Sadraei, and Maryam Fatemeh Sheikholeslami.

\section{Funding/Support}

This study was partially supported by Tarbiat Modares University, Mycobacteriology Research center and the Iranian HIV/AIDS Research Center.

\section{References}

1. Sepkowitz KA. AIDS--the first 20 years. $N$ Engl $J$ Med. 2001;344(23):1764-72.

2. Recommendations for prophylaxis against Pneumocystis carinii pneumonia for adults and adolescents infected with human immunodeficiency virus. MMWR Recomm Rep. 1992;41(RR-4):1-11.

3. Jentsch U, Spencer DA, editors. Causes of mortality in HIV-seropositive patients seen at the Johannesburg Hospital, South Africa, 1991-95.; 36th South African Congress for Pathology and Microbiology..1996; Pretoria.

4. Walkden D, Patel J, Snipeliski M, Heney C, editors. HIV statistics at Baragwanath Hospital, March 1988 to June 1989.; 32nd South African Congress for Pathology and Microbiology..1992; Pretoria.

5. Atzori C, Bruno A, Chichino G, Gatti S, Scaglia M. Pneumocystis carinii pneumonia and tuberculosis in Tanzanian patients infected with HIV. Trans R Soc Trop Med Hyg. 1993;87(1):55-6.

6. Baughman RP, Dohn MN, Frame PT. The continuing utility of bronchoalveolar lavage to diagnose opportunistic infection in AIDS patients. Am J Med. 1994;97(6):515-22.

7. McLeod DT, Neill P, Robertson VJ, Latif AS, Emmanuel JC, Els JE, et al. Pulmonary diseases in patients infected with the human immunodeficiency virus in Zimbabwe, Central Africa. Trans R Soc Trop Med Hyg. 1989;83(5):694-7.

8. van Soolingen D, de Haas PE, Kremer K. Restriction fragment length polymorphism typing of mycobacteria. Methods Mol Med. 2001;54:165-203.

9. Montes-Cano MA, de la Horra C, Martin-Juan J, Varela JM, Torronteras R, Respaldiza N, et al. Pneumocystis jiroveci genotypes in the Spanish population. Clin Infect Dis. 2004;39(1):123-8.

10. Totet A, Latouche S, Lacube P, Pautard JC, Jounieaux V, Raccurt $\mathrm{C}$, et al. Pneumocystis jirovecii dihydropteroate synthase genotypes in immunocompetent infants and immunosuppressed adults, Amiens, France. Emerg Infect Dis. 2004;10(4):667-73.

11. Wakefield AE. DNA sequences identical to Pneumocystis carinii f. sp. carinii and Pneumocystis carinii f. sp. hominis in samples of air spora. J Clin Microbiol. 1996;34(7):1754-9.

12. Allegra CJ, Chabner BA, Tuazon CU, Ogata-Arakaki D, Baird B,
Drake JC, et al. Trimetrexate for the treatment of Pneumocystis carinii pneumonia in patients with the acquired immunodeficiency syndrome. N Engl J Med.1987;317(16):978-85.

13. Peters SG, Prakash UB. Pneumocystis carinii pneumonia. Review of 53 cases. Am J Med. 1987;82(1):73-8.

14. Sattler FR, Cowan R, Nielsen DM, Ruskin J. Trimethoprim-sulfamethoxazole compared with pentamidine for treatment of Pneumocystis carinii pneumonia in the acquired immunodeficiency syndrome. A prospective, noncrossover study. Ann Intern Med.1988;109(4):280-7.

15. Paulson YJ, Gilman TM, Heseltine PN, Sharma OP, Boylen CT. Eflornithine treatment of refractory Pneumocystis carinii pneumonia in patients with acquired immunodeficiency syndrome. Chest. 1992;101(1):67-74.

16. Orlovic D, Kularatne R, Ferraz V, Smego RJ. Dual pulmonary infection with Mycobacterium tuberculosis and Pneumocystis carinii in patients infected with human immunodeficiency virus. Clin Infect Dis. 2001;32(2):289-94.

17. Morris A, Lundgren JD, Masur H, Walzer PD, Hanson DL, Frederick T, et al. Current epidemiology of Pneumocystis pneumonia. Emerg Infect Dis. 2004;10(10):1713-20.

18. Sheikholeslami FM, Sadraei J, Farnia P, Forozandeh M, Emadi Kochak H. Rate of Pneumocystis pneumonia in Iranian HIV+ Patients with Pulmonary Infiltrates. Jundishapur J Microbiol. 2013;6(3):295-300.

19. Aderaye G, Bruchfeld J, Olsson M, Lindquist L. Occurrence of Pneumocystis carinii in HIV-positive patients with suspected pulmonary tuberculosis in Ethiopia. AIDS. 2003;17(3):435-40.

20. World Health Organization.. Global tuberculosis report. 2012. Available from: http://apps.who.int/iris/bitstre am/10665/75938/1/9789241564502_eng.pdf.

21. Sheikholeslami MF, Sadraei J, Farnia P, Forozandeh Moghadam M, Emadi Kochak H. Typing of Pneumocystis jirovecii isolates from Iranian immunosuppressed patients based on the Internal Transcribed Spacer (ITS) region of the rRNA gene. Med Mycol. 2013.

22. Elvin KM, Lumbwe CM, Luo NP, Bjorkman A, Kallenius G, Linder E. Pneumocystis carinii is not a major cause of pneumonia in HIV infected patients in Lusaka, Zambia. Trans R Soc Trop Med Hyg. 1989;83(4):553-5.

23. Kaplan JE, Benson C, Holmes KH, Brooks JT, Pau A, Masur H, et al. Guidelines for prevention and treatment of opportunistic infections in HIV-infected adults and adolescents: recommendations from CDC, the National Institutes of Health, and the HIV Medicine Association of the Infectious Diseases Society of America. MMWR Recomm Rep. 2009;58(RR-4):1-207.

24. Malin AS, Gwanzura LK, Klein S, Robertson VJ, Musvaire P, Mason PR. Pneumocystis carinii pneumonia in Zimbabwe. Lancet. 1995;346(8985):1258-61. 